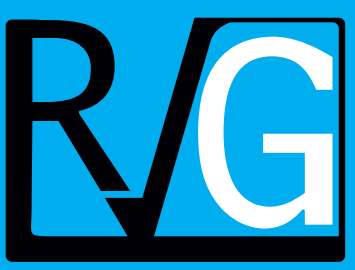

Año 21 No. 74

Abril - Junio 2016

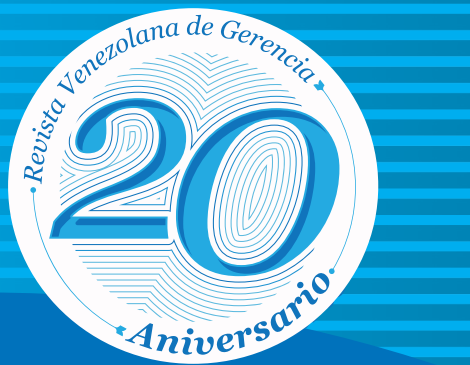

Venezolana de
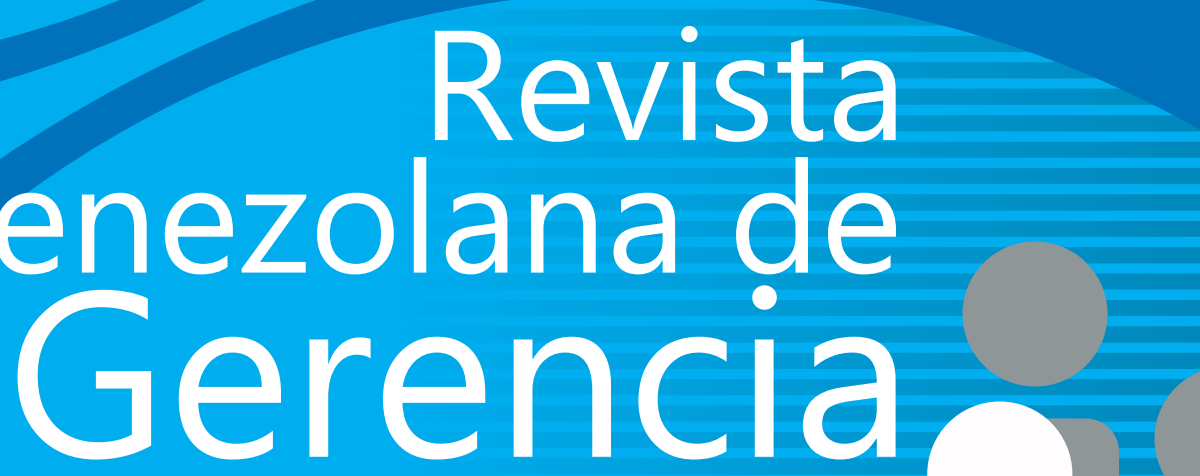


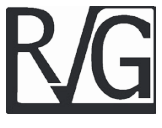

\title{
Participación y contraloría social en la gestión de los consejos comunales en Venezuela*
}

\author{
Montes de Oca Rojas, Yorbeth** \\ Torrealba Carrasco, Jorge** \\ Graterol, Modesto****
}

\section{Resumen}

La Constitución de la República Bolivariana de Venezuela (1999), incorpora los procesos de participación y particularmente de las comunidades organizadas. La contraloría social se apoya en la información generada en los procesos de intervención comunitarios. Los consejos comunales responsables del poder popular estan llamados a la creación de condiciones para la participación y la contraloría social. En el presente artículo, se Explora la participación y contraloría social en la gestión de los consejos comunales del municipio Maracaibo del estado Zulia. La investigación es de tipo descriptiva de campo, se estudian tres consejos comunales de la parroquia Coquivacoa del municipio Maracaibo del estado Zulia. Los resultados dan cuenta de: a) Directrices generales contempladas en la Constitución y en las leyes que argumentan jurídicamente la conformación de los llamados consejos comunales y de contraloría social; b) Los proyectos aprobados y ejecutados permiten avanzar a la conformación de comunas; c) los resultados están orientados a la mejora asistencial de las comunidades en materia de seguridad, alimentación y ambiental. Se concluye sobre la existencia esfuerzos tanto institucionales como sociales en torno a la construcción de una nueva gestión comunitaria que contribuye al fortalecimiento de la participación y la contraloría social.

Palabras clave: participación; contraloría social; gestión; consejos Comunales.

Recibido: 20.04.16 Aceptado: 08.06.16

* Este artículo es resultado del programa de investigación: Información para la gestión, adscrito al Centro de Estudios de la Empresa. Facultad de Ciencias Económicas y Sociales (FCES), Universidad del Zulia.

** Investigadora del Centro de Estudios de la Empresa de la Facultad de Ciencias Económicas y Sociales (FCES). Universidad del Zulia. E-Mail:yorberth@hotmail.com

*** Coinvestigador Auxiliar del Programa Información para la Gestión. E-Mail: jorgealexan2007@ hotmail.com.

**** Director de la Dirección de Relaciones Interinstitucionales. Universidad del Zulia. E-Mail: modestograterol@gmail.com 


\title{
The Comptroller and Social Accountability in Community Councils Municipality Maracaibo Zulia State, Venezuela
}

\begin{abstract}
The Bolivarian Republic of Venezuela's Constitution (1999) incorporates the processes of Accountability and particularly of the community councils. The Social Comproller relies on the information generated by the communities' intervention processes. The community councils responsible of the popular power are called for the creation of Accountability and Social Comptroller This paper analyzes the Comptroller by Social Accountability in Community Councils in Maracaibo, Zulia State, Venezuela, during the period 2008-2011. In this descriptive field research, we study three cases of community councils of the parish Aranza Coquivacoa in Maracaibo, Zulia State. The sources of information were documents and sem-istructured interviews with key subjects. The results show that: 1) General guidelines provided in the Constitution and the laws that legally argue shaping called community councils and Accountability processes and social control; b) social accountability practices that promote social control, c) Lack of a control system to monitor the activities of the communities. The conclusion about the existence of both institutional and social efforts around building a new community management for the development of the country, which if exceeded requires comprehensive care from the highest levels of government.
\end{abstract}

Keywords: accountability; social control; control; management; community councils.

\section{Introducción}

Dos décadas después de haberse iniciado en Venezuela un proceso de desarrollo con orientación neoliberal, se asiste a transformaciones en todos los órdenes, políticos, económicos, sociales, culturales y ambientales, cuyo punto de partida lo constituye un nuevo marco constitucional aprobado a través de un proceso constituyente en 1999, bajo el gobierno del presidente Hugo Chávez.

La Constitución de la República Bolivariana de Venezuela (CRBV), así como las leyes aprobadas en el marco de ésta y los tres Planes de Desarrollo referidos a: Económico y Social (2001-2007), el Plan Socialista Simón Bolívar (2007-2013), y el Plan de la Patria Desarrollo Económico y Social de la Nación (2013-2019), guardan un potencial para dar cuenta de transformaciones institucionales cuyo eje central es promover la participación de las comunidades organizadas y la contraloría social. En consecuencia se plantea una orientación alternativa a la neoliberal, lo cual se deja ver en el preámbulo de la referida carta magna, cuyo propósito es "...refundar la República para establecer una sociedad democrática, participativa y protagónica, multiétnica y pluricultural en un Estado de justicia, federal $y$ descentralizado, que consolide los valores de la libertad, la independencia, la paz, la solidaridad, el bien común, la integridad territorial, la convivencia y el imperio de la ley para esta y las futuras generaciones; asegure el derecho a la vida, al trabajo, a la cultura, a la educación, a la justicia social y a la igualdad sin discriminación ni subordinación alguna...”. 
Participación y contraloría social en la gestión de los consejos comunales... Yorbeth Montes de Oca Rojas, Jorge Torrealba Carrasco, Modesto Graterol

Forma parte del proceso de transformación, la participación por parte de los ciudadanos en el control a la gestión es una de las estrategias de participación, prevista en el nuevo marco legal. Se trata de una forma de participación ciudadana, distinta a la intervención en las decisiones, con un gran potencial para que el aparato público se oriente hacia las necesidades y demandas de los ciudadanos. Esta forma de participación ciudadana se promueve en varios países de América Latina paralelo al impulso de la orientación neoliberal, igualmente el discurso le asigna propósitos de profundización democrática. En Venezuela, constituye un mandato para todos los niveles político-territoriales de la administración pública y para los consejos comunales el involucramiento de los ciudadanos en la gestión.

En el año 2006, se da inicio a la conformación de los consejos comunales en todo el país en la que a través de la asamblea de ciudadanos se eligen de manera popular a los voceros y voceras de su organización la asamblea de ciudadanos, colectivo de coordinación comunitaria, unidad ejecutiva, unidad administrativa y financiera comunitaria y unidad de contraloría social. Los consejos comunales son el medio de articulación y organización de los ciudadanos para resolver problemas colectivos.

Son procesos de transformación institucionales, políticos y comunitarios que tienen lugar en el país desde hace década y media, escasamente se han realizado investigaciones sobre la temática, siendo una necesidad desde el punto de vista crítico construir y explicar la realidad en las comunidades venezolanas,

El propósito de este trabajo, es explorar la participación y contraloría social en la gestión de los consejos comunales de la parroquia Coquivacoa del municipio Maracaibo del estado
Zulia, a partir del estudio de las bases constitucionales y legales sobre participación y contraloría social, y del análisis de documentos producidos en los consejos comunales objeto de estudio, son organizaciones comunitarias alineadas con el gobierno nacional, sin embargo existe involucramiento de ciudadanos con acercamiento a partidos políticos diferentes al gobierno nacional.

La investigación es de tipo descriptiva de campo, se estudian tres consejos comunales (Capitán Chico, Santa Rosa (2da Etapa) y Enmanuel Pulgar), atendiendo a criterios administrativos referidos a los proyectos aprobado por un órgano de financiamiento y ejecutados por las comunidades, esto con el propósito de visualizar la participación y la contraloría social de los ciudadanos en esta parroquia.

La investigación tiene como periodo de estudio 2009-2015, la razón por la cual se ubica este estudio en este período, obedece a la identificación de los siguientes criterios: a) El año 2009 representa una referencia significativa, debido a que se evidencian cambios sustanciales a nivel de la organización comunitaria se crea la Ley Orgánica de los Consejos comunales; más adelante, la Ley Orgánica del Poder Popular (2010), Ley Orgánica de las Comunas (2010), Ley Orgánica de la Contraloría Social, y b) En ese año aparecen referencias fundacionales para el diseño de estrategias sobre la contraloría social, lo cual son esenciales para los procesos de participación y contraloría social.

\section{Participación: Un nuevo modo para involucrarse}

Las discusiones teóricas sobre la participación es presentada desde diferentes puntos de vistas o criterios, 
existen una diversidad de trabajos que destacan la experiencia en América Latina, igualmente surgen las propuestas que durante décadas se han sistematizado, se avanza en la construcción de conceptualizaciones que describen la realidad y el estado del conocimiento sobre la participación especialmente la ciudadana. Se entiende en este trabajo como participación la toma de decisiones que durante la formulación, ejecución y evaluación de la política pública realizan los ciudadanos sobre los ámbitos de lo público, privado y socio-comunitario, el involucramiento de los sujetos clave tienen el propósito de vigilar y darle seguimiento a las decisiones consideradas en las agendas o en el sistema de planificación, en este sentido la necesidad de crear impacto sobre los resultados.

En términos generales, la participación según Cunill (1991: 23), ha sido definida como "...la intervención de la sociedad civil en la esfera de lo público".

El estado actual del conocimiento sobre la participación y especialmente la ciudadana da cuenta de que el término, es utilizado para explicar la incidencia de sujetos clave y grupos sociales en las diferentes etapas en las que se resuelven asuntos de interés público y políticas públicas, es decir, en la consulta, discusiones, evaluaciones, propuestas, y en todo tipo de actividades en las cuales interrelaciona el Estado y los ciudadanos para el progreso de la comunidad.

García (2007), afirma que hablar de la participación, es referir cuando las personas: a) asisten a reuniones en su comunidad; b) manifestaciones en la calle; c) cuando de manera pacífica se niega pública y notoriamente a comprar, hacer o decir algo que la mayoría considera correcto; d) votaciones en proceso electoral; e) ejecución de determinadas tareas; y f) liderazgo en reuniones, la participación bajo está conceptualización toma un carácter general y puede ser ejecutada en la propia gestión realizada por las comunidades organizadas, esto posibilita la creación de nuevos espacios de relación de los ciudadanos, gobiernos, y sus propias gestiones lo cual facilitará procesos de rendición de cuenta, evaluaciones, transparencia y contraloría social en la gestión pública, privada y socialcomunitaria.

Avanzar en esta construcción teórica, es dar cuenta que la participación ciudadana establece condiciones para el ejercicio de la contraloría social, las cuales tienen como finalidad controlar los proyectos y los mismos sean desarrollados con resultados efectivos, tiempo adecuado y costos acordados.

La contraloría social, bajo una perspectiva explicativa, se convierte en una necesidad en América Latina, con serias particularidades en Venezuela, las argumentaciones teóricas generadas son escasas y se soportan en modelos ideales surgidos fuera de la realidad venezolana. Estos problemas de tipo epistemológicos dan cuenta que la producción de conocimiento sobre la contraloría social es escasa.

La administración que ejecutan las organizaciones sociales en Venezuela, se ha caracterizado por una acentuada ineficiencia para justificar acciones y decisiones, de esta manera proponer lineamientos que solventen el déficit creciente de legitimación en la gestión de las políticas comunales que atienden a interés particulares y políticos. En tal razón, la administración recibe constantes exigencias para colocar a la luz pública la información producida de su gestión e incorporar a los ciudadanos en la formulación, seguimiento y evaluación de sus acciones. 
Participación y contraloría social en la gestión de los consejos comunales... Yorbeth Montes de Oca Rojas, Jorge Torrealba Carrasco, Modesto Graterol

\section{Límites para la contraloría social y control social}

Los elementos que ayudan a definir al control social, están referidos históricamente a aspectos vinculados con la criminología para dar cuenta del control ejercido por el Estado a los ciudadanos.

Si bien, este concepto, según González (2004), se remonta a la segunda mitad del Siglo XIX en los Estados Unidos; encontrándose indisolublemente asociado a la impostergable necesidad de integrar en un mismo marco social las grandes masas de inmigrantes, como fuerza de trabajo acudieron a la convocatoria migratoria generada por el proceso de industrialización de la naciente potencia norteamericana; la paternidad científica de la expresión control social pertenece al sociólogo norteamericano Edward Ross, quién la utilizó por primera vez como categoría enfocada a los problemas del orden y la organización del Estado, en la búsqueda de una estabilidad social integrativa resultante de la aceptación de valores únicos y uniformadores de un conglomerado humano disímil en sus raíces étnicas y culturales.

En torno al uso del concepto en la criminología, históricamente se ha generado un debate importante sobre el cual no se hará referencia por cuanto no es objeto de este trabajo; lo importante es destacar que el control social es una categoría analítica de uso comúnmente conocido en el campo de la criminología.

Como proceso que ejercen los ciudadanos sobre el Estado, se usa el término control social, siendo experiencias referenciales los casos de la Contraloría Social (México), Veedurías (Colombia), Vigilancia Social (Bolivia), y
Auditoría Social (Perú) entre otros, sin embargo es útil aclarar, que ha sido a través de la práctica la incorporación de estos últimos términos, caso similar al de Venezuela, que mediante las dinámicas sociales promovidas en las ultima décadas se ha profundizado procesos necesarios para la democracia como lo son la responsabilización, rendición de cuentas, transparencia, gobierno electrónico, participación ciudadana y como parte de ésta la contraloría social.

Mediante la investigación, no se tiene precisión del origen del concepto control social como acción de los ciudadanos sobre la gestión pública, lo más remoto se encuentra en documentos que promueven la Nueva Gestión Pública (NGP) a mediados de los años noventa. Cunill (1991), refiere al clasificar a la participación dependiendo del momento en el cual se realiza, identifica como una fase la evaluación y control, no utiliza ninguno de los términos que hoy se usan para dar cuenta de este proceso, sino refiere a la participación fiscalizadora, la cual define como el involucramiento de los sujetos sociales, sólo en el control de las políticas públicas, distinta a la participación donde se comparten decisiones. Más adelante, la referida autora (Cunill, 2000), utiliza el concepto control social para dar cuenta de un mecanismo para exigir responsabilidad a la administración pública.

Estableciendo diferencias entre los términos control y contraloría social, se evidencia que el término contraloría social, está siendo utilizado en el discurso científico, aparece desde comienzos de los sesenta en la legislación mexicana definido como mecanismo de control de los ciudadanos a la gestión pública, es decir tiene el mismo contenido del término control social (Ochoa y Montes de Oca: 2006). A finales de la década 
pasada mediante la promulgación de Ley Orgánica de los Consejos Comunales en Venezuela se incorpora el uso del término de contraloría social a las intervenciones propias realizadas por los ciudadanos sobre su propia gestión comunitaria.

Fijando posición sobre el uso de los términos participación y contraloría social, es preciso dar respuestas sobre las posibilidades planteadas por las intervenciones que realizan los ciudadanos y las comunidades organizadas sobre su propia gestión "Contraloría Social", en consecuencia contribuirá a una mayor justificación de las acciones y decisiones por parte de los ciudadanos de la gestión y la participación, orientada el involucramiento de los ciudadanos sobre los criterios de la eficacia, eficiencia y efectividad de la gestión comunal.

\section{Bases constitucionales y legales venezolanas para la participación y contraloría social}

Se identifican los lineamientos formales de la participación ciudadana y la contraloría social a partir de la constitución y leyes vinculadas con el objeto de estudio. Con la aprobación en el año 2009 de la Ley Orgánica de los Consejos comunales se aprueban una serie de leyes que le dan viabilidad administrativa y políticas a los consejos comunales como un tipo de organizaciones sociocomunitaria, entre las que se encuentran: Ley Orgánica de los Consejos Comunales (2009), Ley Orgánica de Contraloría Social (2010), Ley Orgánica de las Comunas (2010), Ley Orgánica del Poder Popular (2010), Ley Orgánica del Sistema Económico
Comunal (2010), Ley orgánica de Planificación Pública y Popular (2010) y Ley Orgánica para la Gestión Comunitaria de Competencias, servicios y otras atribuciones (2012), para fines de este apartado se estudiaran la Constitución de la República Bolivariana de Venezuela, Ley Orgánica de los Consejos Comunales (2009), Ley Orgánica de Contraloría Social (2010), por ser el centro de la investigación.

En la Constitución de la República Bolivariana de Venezuela (1999: 2), se evidencian contenidos específicos que orientan a la participación, se ubican nueve (9) artículos vinculados con la participación comunitaria, (4, 5,6 y 51 y $52,62,70,84$ y 132). En sentido general, el artículo 4 , de la CRBV (1999), señala que "la República Bolivariana de Venezuela es un Estado federal descentralizado en los términos consagrados en esta Constitución, y se rige por los principios de integridad territorial, cooperación, solidaridad, concurrencia y corresponsabilidad" (Asamblea Nacional, 1999), mientras que en el artículo 5, se hace mención a que la soberanía reside intransferiblemente en el pueblo, quien la ejerce directamente en la forma prevista en esta Constitución y en la ley, e indirectamente, mediante el sufragio, por los órganos que ejercen el Poder Público" (Asamblea Nacional, 1999). Con estos preceptos constitucionales se deja de manera explícita el poder de los ciudadanos de su soberanía.

En el artículo 6, se establece que el gobierno de la República Bolivariana de Venezuela y de las entidades políticas que la componen, se establecen características relevantes que lo destacan como: "democrático, participativo, electivo, descentralizado, alternativo, responsable, pluralista y 
Participación y contraloría social en la gestión de los consejos comunales... Yorbeth Montes de Oca Rojas, Jorge Torrealba Carrasco, Modesto Graterol

de mandatos revocables" (Asamblea Nacional, 1999:6).

En lo que respecta a los artículos 51 y 52 , ambos hacen referencia a la necesidad y "derechos que tiene toda persona de representar o dirigir peticiones ante cualquier autoridad, funcionario público o funcionaria pública" (Asamblea Nacional, 1999: 16), es decir tiene derechos para acceder a la información y de asociarse con fines lícitos.

Así mismo en el artículo 62 queda establecido como todos los "ciudadanos y ciudadanas tienen el derecho de participar libremente en los asuntos públicos, directamente o por medio de sus representantes elegidos o elegidas" (Asamblea Nacional, 1999: 18), varios artículos se detienen en un tipo de participación: el control por los ciudadanos, particularmente en el derecho que tienen los ciudadanos a ejercer control social en salud (artículo 84) y en la obligación que tienen los Estados y Municipios de promover el control.

En el artículo 70, se expresan los medios de participación y protagonismo del pueblo en ejercicio de su soberanía, en lo político: la elección de cargos públicos, el referendo, la consulta popular, la revocación del mandato, las iniciativas legislativa, constitucional y constituyente, el cabildo abierto y la asamblea de ciudadanos y ciudadanas cuyas decisiones serán de carácter vinculante, entre otros; y en lo social y económico: las instancias de atención ciudadana, la autogestión, la cogestión, las cooperativas en todas sus formas incluyendo las de carácter financiero, las cajas de ahorro, la empresa comunitaria y demás formas asociativas guiadas por los valores de la mutua cooperación y la solidaridad.
En el artículo 132, manifiesta que "toda persona tiene el deber de cumplir sus responsabilidades sociales y participar solidariamente en la vida política, civil y comunitaria del país, promoviendo y defendiendo los derechos humanos como fundamento de la convivencia democrática y de la paz social". En síntesis, (Cuadro 1), la Constitución de la República Bolivariana de Venezuela, incluye elementos que dan cuenta sobre la participación que deben realizar las comunidades organizadas, teniendo deberes y derechos, instancias y espacios participativos en los cuales se convierten en sujetos responsables de involucrarse en la gestión pública, privada y socio-comunitaria.

Se definen de manera constitucional elementos que crean condiciones formales para sistematizar y dar contenido a la participación realizada por los ciudadanos que la misma ayuda abrir posibilidades para la contraloría social en Venezuela.

Son parte de las transformaciones formales sociocomunitarias que en Venezuela tuvieron lugar a principios de esta década, y daba cuenta de un modelo de desarrollo diferente en el que se consolida un proyecto de sociedad alternativo al neoliberal, referido inversiones estatales en vivienda e infraestructura y la promoción del poder popular mediante los consejos comunales, dando paso a un nuevo modo de economía sociocomunitaria necesaria para el desarrollo nacional.

La Ley Orgánica de los Consejos Comunales (LOCC), con su entrada en vigencia deroga la Ley de Los Consejos Comunales del 07 de abril de 2006, en el artículo 2, se menciona que los consejos comunales "son una instancia participativa y protagónica, para la integración 


\section{Cuadro 1 \\ Participación en la Constitución Bolivariana de Venezuela}

\begin{tabular}{|c|c|}
\hline Artículos & Aspectos relevantes \\
\hline $\begin{array}{l}\text { La República Bolivariana de Venezuela es un Estado } \\
\text { federal descentralizado en los términos consagrados en } \\
\text { esta Constitución, y se rige por los principios de integridad } \\
\text { territorial, cooperación, solidaridad, concurrencia y } \\
\text { corresponsabilidad (Art. 4). }\end{array}$ & $\begin{array}{ll}\text { - } & \text { Integridad territorial } \\
\text { - } & \text { Cooperación } \\
\text { - } & \text { Solidaridad } \\
\text { - } & \text { Concurrencia y responsabilidad }\end{array}$ \\
\hline $\begin{array}{l}\text { La soberanía reside intransferiblemente en el pueblo, } \\
\text { quien la ejerce directamente en la forma prevista en esta } \\
\text { Constitución y en la ley, e indirectamente, mediante el } \\
\text { sufragio, por los órganos que ejercen el Poder Público (Art. } \\
\text { 5). }\end{array}$ & $\begin{array}{l}\text { - } \quad \text { Soberanía popular } \\
\text { - } \quad \text { Gobierno democrático }\end{array}$ \\
\hline $\begin{array}{l}\text { Al gobierno de la República Bolivariana de Venezuela y } \\
\text { de las entidades políticas que la componen se establecen } \\
\text { características relevantes que lo destacan como: } \\
\text { democrático, participativo, electivo, descentralizado, } \\
\text { alternativo, responsable, pluralista y de mandatos } \\
\text { revocables (Art. 6). }\end{array}$ & - Derecho a la información \\
\hline $\begin{array}{l}\text { Toda persona tiene el derecho de representar o dirigir } \\
\text { peticiones ante cualquier autoridad, funcionario público } \\
\text { o funcionaria pública sobre los asuntos que sean de la } \\
\text { competencia de éstos o éstas, y de obtener oportuna y } \\
\text { adecuada respuesta. Quienes violen este derecho serán } \\
\text { sancionados o sancionadas conforme a la ley, pudiendo ser } \\
\text { destituidos o destituidas del cargo respectivo (Art. 51). }\end{array}$ & $\begin{array}{l}\text { Derecho de asociarse con fines } \\
\text { lícitos } \\
\text { - Derecho de participación }\end{array}$ \\
\hline $\begin{array}{l}\text { Toda persona tiene el derecho de asociarse con fines lícitos, } \\
\text { de conformidad con la ley. El Estado estará obligado a } \\
\text { facilitar el ejercicio de este derecho (Art. 52). }\end{array}$ & $\begin{array}{l}\text { - Deber de responsabilidad social y } \\
\text { participación solidaria }\end{array}$ \\
\hline $\begin{array}{l}\text { Todos los ciudadanos y ciudadanas tienen el derecho de } \\
\text { participar libremente en los asuntos públicos, directamente } \\
\text { o por medio de sus representantes elegidos o elegidas (Art. } \\
62 \text { ). }\end{array}$ & \\
\hline $\begin{array}{l}\text { Toda persona tiene el deber de cumplir sus responsabilidades } \\
\text { sociales y participar solidariamente en la vida política, civil } \\
\text { y comunitaria del país, promoviendo y defendiendo los } \\
\text { derechos humanos como fundamento de la convivencia } \\
\text { democrática y de la paz social (Art. 132). }\end{array}$ & \\
\hline
\end{tabular}

Fuente: Elaboración propia (2016).

entre los ciudadanos, ciudadanas y las diversas organizaciones comunitarias, movimientos sociales y populares, que permiten al pueblo organizado ejercer el gobierno comunitario y la gestión directa de las políticas públicas y proyectos orientados a responder a las necesidades, potencialidades y aspiraciones de las comunidades, en la construcción del nuevo modelo de sociedad socialista de igualdad, equidad y justicia social" (Asamblea Nacional: 2009).

Con la aprobación de esta ley, el concepto sobre control social es redefinido, ya que en él se asienta el derecho ciudadano a controlar y 
Participación y contraloría social en la gestión de los consejos comunales... Yorbeth Montes de Oca Rojas, Jorge Torrealba Carrasco, Modesto Graterol

fiscalizar, no sólo la ejecución de obras por parte de los diferentes ámbitos de gobierno, sino a ejercerla de igual manera en la ejecución de obras u acciones por parte del propio consejo comunal, es decir, el derecho como ciudadanos de controlarse así mismo, lo que de hecho amplia la noción de contraloría social, al definirla entonces como la potestad que tiene el ciudadano de intervenir en la gestión pública, social y la privada, mediante los mecanismos que crea necesarios, a esto se llamará Contraloría Social.

De acuerdo con el artículo 19, de la LOCC, son cinco instancias administrativas que definen la organización y estructura de los consejos comunales, a saber: a) asamblea de ciudadanos y ciudadanas, b) colectivo de coordinación comunitaria, d) unidad ejecutiva, e) unidad administrativa y financiera comunitaria, y f) unidad de contraloría social (Asamblea Nacional: 1999). El órgano de toma de decisiones es la asamblea de ciudadanos. Su órgano ejecutivo está integrado por un vocero o una vocera de cada comité de trabajo de la comunidad, cinco miembros de la unidad administrativa y financiera y cinco de la unidad de contraloría social.

La asamblea de ciudadanos y ciudadanas, es el órgano de decisión y aprobación de proyectos, y es la que decide sobre la conformación de los comités de trabajo, los cuales varían de acuerdo con las necesidades de las comunidades, tales como: comité de salud (que apoya a los médicos de la Misión Barrio Adentro en el trabajo de prevención), mesas técnicas de agua (MTA, que elaboran junto a las entidades de suministro de agua los planes para sus zonas), comités de tierra urbana (CTU), comités de ambiente, cultura, deportes, jóvenes, abuelos, economía popular, educación, desarrollo social y alimentación, vivienda, infraestructura y hábitat, justicia de paz, seguridad y defensa, radio comunitaria entre otras.

Los voceros y las voceras forman el órgano ejecutivo que se encarga de la planificación y articulación de la participación organizada de la comunidad. La unidad financiera es el administrador y ejecutor de los recursos del Banco Comunal, y es el medio a través de la cual la comunidad puede otorgar créditos en condiciones favorables a la misma comunidad, según las prioridades decididas por los mismos, siendo la contraloría social la encargada de revisar y fiscalizar el manejo de los ingresos, detectar desviaciones y sugerir y sistematizar correcciones (cuadro 2).

Por otro lado, surge en el año 2010, la Ley Orgánica de Contraloría Social LOCS, la cual establece en el artículo 1, la contraloría social es un medio de participación y define como medios de prevención, vigilancia, supervisión y control de la gestión pública y comunitaria (Asamblea nacional: 2010), está ley abre la posibilidad para que los ciudadanos vigilen e intervengan gestiones publicas privadas y sociocomunitarias.

Se identifican las responsabilidades a los voceros y voceras, en el artículo 8 , se establece que todos deben cumplir con sus funciones, de igual manera deben informar a sus colectivos sobre las actividades, avances y resultados de las acciones de prevención, supervisión, vigilancia, evaluación y control del área o ámbito de actuación de la organización, en tal sentido Montes de Oca (2012), expresa que las "...directrices generales contempladas en la Constitución y en las leyes que argumentan jurídicamente la conformación de los llamados consejos comunales y de procesos de contraloría social", dando 


\section{Cuadro 2}

\section{Ley Orgánica de los Consejos Comunales}

\begin{tabular}{|c|c|}
\hline Artículos & Aspectos Relevantes \\
\hline $\begin{array}{l}\text { Los consejos comunales, en el marco constitucional de la } \\
\text { democracia }\end{array}$ & \\
\hline $\begin{array}{l}\text { participativa y protagónica, son instancias de participación, } \\
\text { articulación e integración entre los ciudadanos, ciudadanas } \\
\text { y las diversas organizaciones comunitarias, movimientos } \\
\text { sociales y populares, que permiten al pueblo organizado } \\
\text { ejercer el gobierno comunitario y la gestión directa de } \\
\text { las políticas públicas y proyectos orientados a responder } \\
\text { a las necesidades, potencialidades y aspiraciones de las } \\
\text { comunidades, en la construcción del nuevo modelo de } \\
\text { sociedad socialista de igualdad, equidad y justicia social } \\
\text { (Art. 2). }\end{array}$ & $\begin{array}{l}\text { - } \quad \text { Proyectos } \\
\text { Organización de las } \\
\text { comunidades } \\
\text { lgualdad, equidad y justicia } \\
\text { social. }\end{array}$ \\
\hline $\begin{array}{l}\text { La organización de los consejos comunales, quedó } \\
\text { conformada por: La asamblea de ciudadanos y ciudadanas } \\
\text { del consejo comunal, el colectivo de coordinación } \\
\text { comunitaria, la unidad ejecutiva, la unidad administrativa y } \\
\text { financiera comunitaria, la unidad de contraloría social (Art. } \\
\text { 19) }\end{array}$ & $\begin{array}{l}\text { - Organización y estructura } \\
\text { organizativa }\end{array}$ \\
\hline
\end{tabular}

Fuente: Elaboración propia (2016).

cuenta de que existen disposiciones jurídicas que definen los procesos y las consideraciones generales de los consejos comunales, para la toma de decisiones y la contraloría social.

Como sujetos para ejercer la contraloría social la LOCS, identifica a los voceros y voceras del poder popular, a los ciudadanos y a las comunidades organizadas; en el artículo 9, refiere los siguientes medios de contraloría social: a) individuales, orientados a la persona, cuando formula o dirige una solicitud, observación o denuncia sobre asuntos de su interés particular o se relacione con el interés colectivo, b) colectivos, por iniciativa popular, conformadas por dos o más personas, para ejercer el control de manera temporal sobre una situación específica y circunstancial; o permanente, referidos a cualquier actividad del ámbito de la contraloría social, $Y$ finalmente la c) Orgánicos, cuando sean creados mediante ley, estableciéndoseles su forma de organización, integración, funcionamiento y ámbito de actuación (Asamblea Nacional: 2010).

Para efectos de su operatividad, los consejos comunales elegirán democráticamente en asamblea de sus integrantes, a voceros o voceras con sus respectivos suplentes, quienes ejercerán la expresión de la organización ante el resto de la sociedad y deberán rendir cuenta de sus actuaciones ante los demás integrantes de su colectivo.

El artículo 13, refiere a los lineamientos para el establecimiento de procedimientos, refiere que podrá realizarse mediante denuncia, noticia de oficio, según sea el caso; por toda persona natural o jurídica, con conocimiento en los hechos que conlleven a una posible infracción, 
Participación y contraloría social en la gestión de los consejos comunales... Yorbeth Montes de Oca Rojas, Jorge Torrealba Carrasco, Modesto Graterol

irregularidad o inacción que afecte los intereses individuales o colectivos de los ciudadanos y ciudadanas, de la manera siguiente:

a) Notificar directamente al órgano competente local, regional 0 nacional, para la apertura del inicio de la investigación a los efectos de comprobar la presunta infracción, irregularidad o inacción.

b) Realizada la función de contraloría social y efectivamente presumirse las infracciones, omisiones o hechos irregulares, se levantará un acta suscrita por quien o quienes integren la contraloría social, en la cual se dejará constancia fiel de los hechos, acompañada de la documentación que soporte los mismos, la cual tiene carácter vinculante para los organismos receptores.

c) Remitir el acta vinculante, indicada en el numeral anterior, ante las autoridades administrativas, penales, judiciales o de control fiscal que corresponda.

d) Hacer seguimiento de los procedimientos iniciados ante las autoridades administrativas, penales, judiciales $\mathrm{o}$ de control fiscal que corresponda, con el objeto de mantener informado a la organización de contraloría social a la que pertenezca (Asamblea nacional: 2010).

Más allá de la existencia de un marco legal que promueve la contraloría social, existe una incorporación en el discurso de los voceros y voceras así como de los ciudadanos en general, que hace referencia a la contraloría social, como un nuevo proceso que va más allá de la participación ciudadana, y se convierte en nuevos términos asociados a los procesos democratizadores que tienen lugar en Venezuela y dan cuenta de una política pública definida hacia la construcción de un poder popular (Cuadro 3).

\section{Cuadro 3}

Ley Orgánica de la Contraloría Social (2010)

\begin{tabular}{|c|c|}
\hline Artículos & Aspectos Relevantes \\
\hline \multicolumn{2}{|l|}{ La sociedad civil organizada (Art.6) } \\
\hline Políticas, programas y proyectos de la gestión pública (Art.6) & Autonomías \\
\hline $\begin{array}{l}\text { Agrupaciones sin fines de lucro, lo cual se entiende como } \\
\text { Sociedad Civil Organizada (Art.22) }\end{array}$ & $\begin{array}{l}\text { - } \quad \text { Participación Ciudadana } \\
\text { - } \quad \text { Control y evaluación de }\end{array}$ \\
\hline $\begin{array}{l}\text { Gestión y ejecución de obras o administración de los servicios } \\
\text { (Art.30) }\end{array}$ & \\
\hline $\begin{array}{l}\text { Todo ciudadano y ciudadana tienen el derecho de participar } \\
\text { libremente en los asuntos públicos, directamente o por medio } \\
\text { de sus representantes elegidos o elegidas (Art. 62). } \\
\text { La comunidad organizada (Art. 84). }\end{array}$ & $\begin{array}{l}\text { - } \quad \text { Derechos de participación } \\
\text { - Organización de las } \\
\text { comunidades }\end{array}$ \\
\hline Comunidades, ciudadanas y ciudadanos (Art. 184) & Ciudadanos \\
\hline
\end{tabular}

Fuente: Elaboración propia (2016). 


\section{Experiencia de la participación y la contraloría social en los consejos comunales de la parroquia Coquivacoa}

La contraloría social es un tipo de participación que en su discurso queda contemplada en los lineamientos de la nueva gestión pública, y los consejos comunales, como instancia de participación comunitaria, responsables de la gestión directa de las políticas públicas y proyectos comunitarios orientados. Son a la vez instancias clave para la construcción de las comunas (Consejos comunales, colectivos y misiones sociales), con vinculaciones potenciales entre el nivel local, regional y nacional.

En total son 250 consejos comunales conformados en la parroquia Coquivacoa desde el año 2006 (Fundacomunal: 2010), en las cuales descansó la gestión de proyectos y programas sobre los problemas de sus sectores, el gobierno nacional ha impulsado la gestión sociocomunitaria como parte de la transformación institucional que desde el año 1999, tiene lugar en Venezuela.

Desde el año 2006, estos consejos comunales se han conformado en varios sectores de la parroquia Coquivacoa y han asumido responsabilidades que antes eran atendidas por el aparato público, y ahora asumen la administración de áreas de trabajo sobre ambiente, tierras urbanas; salud, deporte y recreación, cultura, hábitat y vivienda; economía comunal; recreación; alimentación y distribución de alimentos, mesa técnica de energía gas; protección social, niños y adolescentes; mujeres maltratadas, inseguridad, protección e igualdad social; adulto mayor; personas con discapacidad, entre otras, como generadoras de soluciones a los problemas inmediatos comunitarios. Adicionalmente se han involucrado en la formación de programas y proyectos con similitudes al del gobierno nacional.

Los consejos comunales

Capitán Chico, Santa Rosa (2da Etapa) y Enmanuel Pulgar, los mismos son instancias comunitarias que han formulado y ejecutado proyectos de mejora de infraestructura $y$ ambientalistas, $y$ han avanzado en la conformación de comunas a continuación se caracterizan:

Loa asuntos relacionados con la participación y la contraloría social, dan cuenta del método, se trata de buscar sistematizar las intervenciones exitosas y los procesos de transformación que tienen lugar ejecutando acciones de participación y contraloría, si bien los sujetos que participan son fundamentales y se representan en equipos promotores, asamblea de ciudadanos y ciudadanas, equipos electorales provisionales, voceros y voceras, colectivos de coordinación comunitaria, unidades ejecutivas, unidad administrativa $y$ financiera y la unidad de contraloría social (Ley Orgánica de Contraloría Social: 2010; Art. 19, 24, 28, 29), son diversos los sujetos que formalmente participan pero a su vez también pueden generar procesos de contraloría social, los mismos definen procedimientos sobre los procesos y resultados de la gestión comunal, mediante reclamos y solicitud de correcciones a las desviaciones encontradas.

Al consultárseles mediante las entrevistas semiestructurada a los consejos comunales objeto de estudio, sobre la necesidad de que los voceros 
Participación y contraloría social en la gestión de los consejos comunales... Yorbeth Montes de Oca Rojas, Jorge Torrealba Carrasco, Modesto Graterol

\begin{tabular}{|c|c|c|c|c|c|}
\hline Parroquia & Población & $\begin{array}{l}\text { Consejo } \\
\text { Comunal }\end{array}$ & $\begin{array}{l}\text { Ubicación } \\
\text { Zona Este }\end{array}$ & Actividades & $\begin{array}{c}\text { Número de } \\
\text { Voceras y } \\
\text { Voceros } \\
\text { entrevistados }\end{array}$ \\
\hline Coquivacoa & $\begin{array}{l}97.762 \\
\text { habitantes }\end{array}$ & $\begin{array}{l}\text { Capitán Chico } \\
\text { Santa Rosa 2da } \\
\text { Etapa } \\
\text { Enmanuel Pulgar }\end{array}$ & $\begin{array}{l}\text { Se ubicada al norte del } \\
\text { Municipio Maracaibo, } \\
\text { limita al noroeste con } \\
\text { el Lago de Maracaibo, } \\
\text { por el este colinda con } \\
\text { la punta Capitán Chico } \\
\text { y la zona palafítica de } \\
\text { Santa Rosa de Agua, } \\
\text { donde se extiende } \\
\text { hasta la prolongación } \\
\text { N}^{\circ} 2 \text {, limita al sur con } \\
\text { la Parroquia Olegario } \\
\text { Villalobos y al oeste } \\
\text { con Juana de Ávila }\end{array}$ & $\begin{array}{l}\text { Jornadas } \\
\text { culturales, } \\
\text { ambientales y } \\
\text { deportivas } \\
\text { Vigilancia en } \\
\text { la construcción } \\
\text { de canchas } \\
\text { deportivas } \\
\text { Conformación } \\
\text { de la Comuna } \\
\text { Añu Santa Rosa } \\
\text { de Agua }\end{array}$ & $\begin{array}{l}30 \text { ciudadanos } \\
\text { y ciudadanas, } \\
10 \text { voceros y } \\
\text { voceras de } \\
\text { cada consejo } \\
\text { comunal }\end{array}$ \\
\hline
\end{tabular}

Fuente: Elaboración propia (2016) A partir de Instituto Nacional de Estadística (INE) (2012).

y voceras de las diferentes unidades de gestión, con especial atención la unidad de contraloría social se responsabilicen en igualdad de condiciones para hacerle seguimiento a las desviaciones encontradas en los proyectos, los ciudadanos entrevistados afirmaron que los procesos de vigilancia y coordinación los realizan teniendo en consideración los procesos de diseño y elaboración de los proyectos, si bien los consejos comunales Capitán Chico, Santa Rosa (2da Etapa) y Enmanuel Pulgar; demuestran características similares en la que los sujetos establecen diversos medios para la obtención de la información, todos los sujetos involucrados en la gestión comunal deben presentar información de los ejecutado y por ejecutar.

En esta parroquia se construyó el Parque Comunal Manglares Tierra de Sueños, parque ecoturístico, resultado de un esfuerzo mancomunado entre la Fundación Azul Ambientalistas y el consejo comunal Capitán Chico, en conjunto con el Centro de Educación
Popular Jesús Rosario Ortega, que ofrece a todos los interesados un recorrido interno, y de acuerdo con las entrevistas realizadas es el único destino ecoturístico del Municipio Maracaibo, los gastos generados en la ejecución de este proyecto, ameritan vigilancia, supervisión y demostración pública de lo realizado o por realizar; no deja de llamar la atención, que en estas formas organizativas no se realice control administrativo de los fondos asignados para la ejecución de proyectos por sus respectivas comunidades y de las responsabilidades administrativas $y$ políticas de los voceros y voceras.

A partir de las reformas jurídicas aprobadas en el 2010, entre ellas la Ley Orgánica de las Comunas (2010), Ley Orgánica de la Contraloría Social (2010) y la Ley Orgánica del Poder Popular (2010); todos los consejos comunales, al manejar fondos públicos, generan responsabilidad civil, penal y administrativa, tal como queda contemplado en el artículo 14, sobre las responsabilidades de la ley Orgánica 
de la Contraloría Social; aunque no existen reglamentaciones especificas referidas a la responsabilidad de los miembros del consejo comunal desde la Ley del Estatuto de Funcionario Público, los miembros del órgano financiero adquieren las responsabilidades propias de un Funcionario Público.

El método da cuenta de la participación de voceras y voceros en la formulación del proyecto y del ejercicio de la contraloría social durante la ejecución, y tímidamente se logra obtener información de los proyectos y trámites administrativos para realizar evaluaciones internas y externas de los resultados obtenidos y del impacto social causado.

$\mathrm{Si}$ bien es preocupante las afirmaciones de los voceros y voceras de estas instancias sociales por la ausencia en la realidad de medios de control sobre el dinero y el financiamiento que reciben por parte del gobierno nacional, regional y municipal; lo cual realizan reflexiones interesantes sobre la corrupción en estas comunidades.

El estudio realizado a las bases constitucionales y legales estudiadas, escasamente se identifican lineamientos jurídicos que les permitan a los ciudadanos de manera individual $o$ a través de organismos sociales, acceder a la autoridad de control o judicial para exigir la responsabilización de los miembros de los consejos comunales, un recurso clave, es sin duda, el derecho de petición que consiste en la facultad que tiene cualquier persona para poder dirigirse a la autoridad solicitando algo y el deber de esta de contestar por escrito (El Troudi y col.: 2005). Se ha destacado que representa el antecedente jurídico más importante que posibilita la colaboración de la ciudadanía en diversos ámbitos, destacando su participación en la contraloría social.

Las entrevistas realizadas, dan cuenta de una vinculación entre lo planificado en planes y programas ambientales en la parroquia Coquivacoa y lo que se controla, a pesar de que las comunidades no tienen teóricamente claro el significado de los criterios de eficacia, eficiencia y efectividad, las actividades que se realizan están referidas al ahorro de los recursos de manera de ampliar su cobertura y que atienda a la colectividad, y en su mayoría se ha logrado modificar y crear un impacto positivo y significativo en las comunidades.

Los objetivos establecidos en los proyectos, programas y planes, se cumplen, lo cual da cuenta de la eficacia de los aspectos que se controlan internamente en los consejos comunales en materia ambiental. Se destaca el ahorro de recursos en general en el cumplimiento de los objetivos programados, y se afirma que lo planificado por el comité de ambiente, ha sido vigilado siempre generando modificaciones sustanciales.

\section{Reflexiones finales}

La partición se constituye en un método que puede contribuir a activar a la contraloría social a la gestiones sociocomunitarias y avanzar en la construcción del poder ciudadano, especialmente si se crean condiciones para la definición de métodos de participación y de contraloría que es el caso de la parroquia Coquivacoa a raíz de la promulgación de la Constitución de la República Bolivariana de Venezuela y con base en ésta, del impulso de un proceso de transformación comunitaria.

A pesar de que se han creado condiciones jurídicas y políticas para avanzar en la contraloría social a la gestiones sociocomunitarias, entre ellas la creación de una unidad administrativa 
en el consejo comunal sobre contraloría social y el derecho a la información y a la participación en la formulación de las políticas públicas, lejos se está de poder activar la contraloría social como método de vigilancia que establezca sanciones y frene los actos de corrupción, esto se demuestra en los resultados encontrados en los consejos comunales que destacan formas imprevistas de legitimación y la conformación de grupos que atienden sus propios intereses y $\mathrm{n} o$ los colectivos.

Los consejos comunales son instancias comunitarias que manejan recursos financieros por los proyectos comunitarios aprobados y sus miembros tienen responsabilidades penales $y$ administrativas a raíz de la construcción del poder ciudadano desde mediados del 2000. Los consejos comunales tienen su unidad de contraloría social conformados y realizan sus actividades de vigilancia y control, sin embargo la información que obtienen siempre es manejada según el criterio político del momento, y no tiene potencial para contribuir al proceso de profundización democrática y la legitimación como comunidades organizadas para llevar a causar impactos con los resultados obtenidos. Lo expuesto revela que es necesario avanzar en la creación de condiciones administrativas y políticas que garanticen que garanticen a los consejos comunales contribuir a profundizar la participación comunitaria mediante la contraloría social.

\section{Referencias Bibliográficas}

Asamblea Nacional (2009). Ley Orgánica de los Consejos Comunales. Gaceta Oficial 39335. Caracas, Venezuela.

Asamblea Nacional Constituyente (1999). Constitución de la República
Bolivariana de Venezuela. Caracas Venezuela.

Asamblea Nacional de la República Bolivariana de Venezuela (2010). Ley Orgánica de las Comunas. Gaceta Oficial $N^{\circ} 6.011$. Venezuela.

Asamblea Nacional de la República Bolivariana de Venezuela (2010). Ley Orgánica de la Contraloría Social. Gaceta Oficial 37573. Caracas.

Consejo Nacional Electoral (CNE) (2004). Cifras del referéndum consultivo de agosto de 2004. Consulta realizada en julio.

Cunill Grau, Nuria (2000). Responsabilización por el control social. En: La responsabilización en la Nueva Gestión Pública Latinoamericana. CLAD, BID y EUDEBA. Buenos Aires.

Cunill, Nuria. (1991). Participación ciudadana. Dilemas y perspectivas para la democratización de los estados latinoamericanos. Caracas: Centro Latinoamericano de Administración para el Desarrollo.

El Troudi, H., Harnecker, M. y Bonilla-Molin, L (2005). Herramientas para la participación. Caracas: Corporación Venezolana de Guayana.

García Guadilla (2007). El poder popular y la democracia participativa en Venezuela: Los consejos comunales.

González Rodríguez, Martha (2004). Análisis del control social desde una perspectiva histórica. www. monografías.com. Consulta realizada en julio.

Instituto Nacional de Estadística (INE) (2012). XIII Censo General de la Población y Vivienda. En: www.ine.gob.ve Consulta realizada en Enero 2012.

Ministerio de Planificación y Desarrollo (2001). Líneas Generales del Plan de Desarrollo Económico y Social de la Nación 2001- 2007. Hugo Chávez Frías. Mimeo. Caracas-Venezuela.

Ministerio del Poder Popular para las Comunas y Protección Social (2010). Prensa Comunal. Caracas Venezuela.

Ochoa Haydée y Montes de Oca Yorberth (2006). Control Social. Una realidad o una necesidad. Líneas Generales del Proyecto de Investigación Centro de Estudios de la Empresa Y FONACIT. 


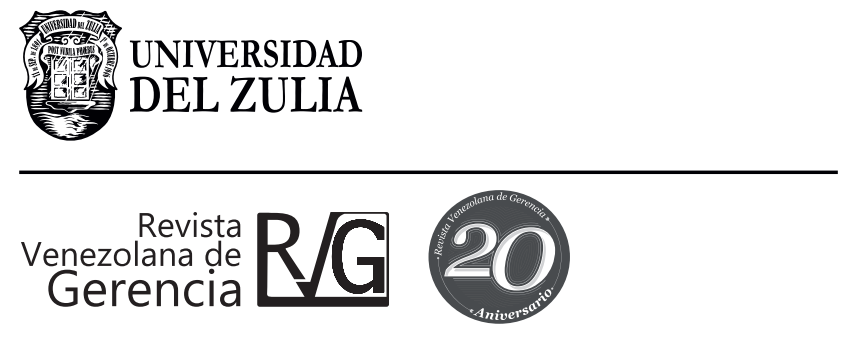

Año 21, No. 74

Esta revista fue editada en formato digital y publicada en junio del 2016, por la Universidad del Zulia, Vicerrectorado Académico, Serbiluz - Fondo editorial, Maracaibo -Venezuela. 